\title{
The fabrication of the complex bio-fertilizer for wheat cultivation based on collection bacteria of the PGPR group
}

\author{
RAKHILYA AIPOVA ${ }^{1}$, AIZHAN ABDYKADYROVA ${ }^{1}$, DMITRY SILAYEV ${ }^{1}$, ERKIN TAZABEKOVA $^{2}$, \\ IRINA OSHERGINA ${ }^{3}$, EVGENIY TEN ${ }^{3}$, ASKAR KURMANBAYEV ${ }^{1, \bullet}$ \\ ${ }^{1}$ National Center for Biotechnology, Ministry of Education and Science. Korgalzhyn Shosse, 13/5, Nur-Sultan, 010000, Kazakhstan. \\ Tel.: +77-271707518, `email: kurmanbayev2021@list.ru \\ ${ }^{2}$ Kazakhstan-Belarus Center Scientific and Technical Cooperation, Eurasian National University, named after L.N. Gumileva. Satpayev St., Nur-Sultan, \\ 010000, Kazakhstan \\ ${ }^{3}$ Scientific-Production Center for Grain Farming, named after A. Barayev. Akmola Region, Shortandy District, Shortandy-1, Barayev St. 1, Kazakhstan
}

Manuscript received: 19 August 2020. Revision accepted: 6 October 2020.

\begin{abstract}
Aipova R, Abdykadyrova A, Silayev D, Tazabekova E, Oshergina I, Ten E, Kurmanbaye A. 2020. The fabrication of the complex bio-fertilizer for wheat cultivation based on collection bacteria of the PGPR group. Biodiversitas 21: 5032-5039. The development of new types of biological products based on microbial complexes from local bacterial strains is a great theoretical and practical interest for agriculture. It can provide an opportunity for better preservation of the natural properties of the wheat products under extreme conditions. The aim of this study was to obtain and test a biological product to increase wheat productivity in northern Kazakhstan. Our data indicate the potential of Plant Growth-Promoting Rhizobacteria (PGPR) group bacteria for the development of biofertilizers and biopesticides. For instance, the bacteria B. mojavensis showed effectiveness in the experiments with the wheat (Astana-2 type). We observed an increase in wheat yield by $15 \%$ under conditions of artificial infection of crops with snow mold (by 2.5fold compared with the control). The results demonstrated that the B. mojavensis Lhv 97 strain can be used as an ingredient of biological products due to its activity against plant diseases caused by phytopathogenic fungi.
\end{abstract}

Keywords: Bacteria, biofertilizers, nitrogen fixation, phosphate mobilization, plant growth stimulation

\section{INTRODUCTION}

The understanding of the enormous biological diversity of the planet has led to the necessity to preserve such diversity in nature (in-situ), including national parks, sanctuaries, etc. and ex-situ conditions: in special collections, bio-banks, and biological resource centers.

The impact of climate change is expected to impose more environmental stresses on crops worldwide (Backer et al. 2018). In agriculture, especially in the framework of the concept of organic farming, there is a growing interest in the use of microorganisms that can positively affect not only the crop of plants, but also soil fertility. The most effective in this regard is the group of rhizospheric microorganisms that have a favorable effect on the growth and development of plants. This group is called PGPRPlant Growth-Promoting Rhizobacteria (Smith et al. 2014). In fact, Rhizospheric microorganisms attracted the attention of biotechnologists due to their high potential for the development of bio-fertilizers, bio-pesticides, and plant growth stimulants (Kumari et al. 2019).

PGPR bacteria affect the plant by changing the entire microbial community in the rhizosphere niche through the synthesis of various substances. As a rule, PGPR promotes plant growth directly due to its ability to supply the plant with nutrients (nitrogen, phosphorus, potassium, and other vital minerals). In addition, PGPRs are able of modulating the levels of plant hormones or indirectly reducing the inhibitory effect of various pathogens on plant growth and development in the form of biopesticides, colonizers of roots, and environmental protection (Umesha et al. 2018; Kumari et al. 2019).

At present, growth-stimulating rhizobacteria have been classified into two groups: extracellular and intracellular PGPR. Bacterial births such as Agrobacterium, Arthrobacter, Azotobacter, Azospirillum, Bacillus, Burkholderia, Caulobacter, Chromobacterium, Erwinia, Flavobacterium, Micrococcus, Pseudomonas, and Serratia belong to the first group. The second group includes bacteria of the Rhizobiaceae family, including the species Allorhizobium, Bradyrhizobium, Mesorhizobium and Rhizobium, endophytes, and Frankia, which can symbiotically fix atmospheric nitrogen with higher plants (Shirokih et al. 2007). It was shown that PGPR can stimulate plant growth through nutrient recycling, nitrogen fixation, phytohormone production, solubilization of nutrients such as $\mathrm{P}, \mathrm{K}$, and $\mathrm{Fe}$, and promoting plant resistance to pests and diseases (Gange and Gadhave 2018).

Thus, collections of rhizobacteria can play an important role in the practice of plant growing, ecological farming, and disease control. In this study, we tested and validated the possibility of the use of PGPR bacteria for the development of the bio-fertilizer for spring wheat. The ultimate goal of this study was to obtain and test a biological product to increase wheat productivity in northern Kazakhstan. 


\section{MATERIALS AND METHODS}

The studies were performed on the laboratory of environmental biotechnology of the National Center for Biotechnology of the Ministry of Education and Science of the Republic of Kazakhstan, Nur-Sultan, Kazakhstan. The work was carried out using the Laminar flow Cabina "ESCO" laminar box, Innova 43 shakers-the Incubator Shaker Series (New Brunswick Scientific), Consort C932 pH meters "SI Analytics Prolab 3000", Ultrospec 7000 spectrophotometers, etc.

Rhizobacteria were isolated from the root system of spring wheat, selected on the fields of the SPCGF (Majeed et al. 2015). The identification of PGPR strains was carried out by determining the direct nucleotide sequence of the 16SrRNA fragment of the gene, followed by determination of the nucleotide identity with the sequences deposited in the international GeneBank database. The identification of microorganisms was conducted on the basis of comparing data on the composition and ratio of peptides obtained by hydrolysis of proteins in the colony of the studied microorganism with similar data of typical strains from the MALDI Biotyper v database. 2.0.4. (Bruker Daltonik, Germany) (Dingle and Butler-Wu 2013).

Evaluation of the activity of PGPR bacteria was carried out in laboratory, vegetative, and field conditions. Bacterial properties such as stimulation of the growth of wheat seedlings, the ability to fix atmospheric nitrogen, mobilize the sparingly soluble soil phosphates, and inhibit the growth of phytopathogenic micromycetes were evaluated.

In order to assess the effect of bacterial strains on seed germination, sterilized, and treated with a bacterial suspension of the corresponding culture wheat seeds were used. The effect of bacteria on germination of plant seeds was evaluated (Sharifi and Khavazi 2011). The following parameters were taken into account: seed germination, the length of the above-and underground parts of the seedling. The percentage of seeds germinated over half of the period necessary for calculating the germination of seeds (growth period-3.5 days) was used as evaluation criteria.

The effectiveness of bacteria as bio-fertilizers was assessed in vegetation experiments. Wheat plants were grown in a greenhouse in vegetation vessels filled with 2 $\mathrm{kg}$ of soil. The soil without microbial fertilizers was used as a control. 10 seeds of one plant were placed in each pot. The cultivation duration was 92 days. To measure the value of the aboveground and underground parts of plants, they were extracted from the soil, the shoots and roots of the plants were separated from each other and their length was measured. To determine the biomass of plants, shoots, and roots were dried for 7-9 hours at $70^{\circ} \mathrm{C}$ to a dry state and their weight was measured according (Cruz-González et al. 2017).

Field experiments were carried out according to the stubble background (the predecessor was spring barley) on field № 5. Field preparation and experiments were conducted according to the recommendations of Kazakh Research Institute of Grain Management, with particular additions and changes approved by A.I. Barayev Grain Farm. Pre-sowing tillage was performed by SKP-2.1 sewing machine on 10-12 $\mathrm{cm}$. Sowing was carried out at the optimum time on May 20. Seed material is sown manually in plots with an area of $12 \mathrm{~m}^{2}$, sextuple repetitions, with a seeding rate of 300 germinating seeds per one $\mathrm{m}^{2}$. Crop care consisted of loosening of horizons and paths with a mounted cultivator and weeding manually. Methods and techniques for testing experiments conventional for cereal crops. All estimates, observations, crop accounting were performed in accordance with the methodology of state variety testing of agricultural crops. During the ripening period, before harvesting the plots, a structural sheaf is taken from accounting sites. During the laboratory analysis, the following elements of the crop structure are taken into account: productive bushiness, plant height, spike length, number of spikelets, number of grains, weight of grain per spike, amount of grain per plant, weight of grain per plant.

The concentration of soluble phosphates was determined in the culture fluid. The method is based on the determination of inorganic soluble phosphates $\left(\mathrm{PO}_{4}\right)$ formed in the culture fluid from insoluble $\mathrm{Ca}_{3}\left(\mathrm{PO}_{4}\right)_{2}$ by binding them with a vanadium-molybdenum reagent with the formation of a yellow phosphorus-vanadiummolybdenum complex with an absorption maximum of 410 $\mathrm{nm}$.

A qualitative determination of the nitrogen-fixing ability of bacteria was carried out using the method of screening the studied strains grown on a nitrogen-free mineral medium (NFMM-nitrogen-free mineral medium), using glucose as a carbon source.

Accounting for the crop was carried out by the weight method (Dospekhov 2012). Statistical processing of the data was implemented. All experiments were performed in triplicate. Quantitative data were subjected to statistical processing using generally accepted mathematical methods to calculate the arithmetic mean value, standard deviation, and mean square error. Performing statistical calculations, building histograms, and diagrams were carried out in semi-automatic mode using Microsoft Office Excel 2007.

Experimental samples of a liquid biofertilizer formulation for vegetation experiments were prepared by mixing liquid culture of strains with an adhesive of $4 \%$ sucrose. For inoculation into flasks, a bacterial suspension of a 24-hour culture washed from Petri dishes was used. The initial optical density in flasks considered as $1 \times 10^{8}$ $\mathrm{CFU} / \mathrm{ml}$ according to the McFarland turbidity standard (Kuhn and Grof 2010).

Method of application: 2 hours before sowing, the seeds were treated with bacterial culture of biofertilizer and thoroughly mixed manually. The seeds in the control variant were moistened with distilled water.

Infectious background: natural, without the introduction of basic fertilizer and without protecting crops from diseases. The repetition in the experiments is 6-fold, the placement of variants is systematic and the accounting area of the plot is $12 \mathrm{~m}^{2}$. The structure of the crop was analyzed according to the methodology of state variety testing of crops (Luna et al. 2014). To determine the structure of the crop used model sheaves from the accounting sites, which were selected before harvesting. The number of plants, the 
length of the stem, the upper internode, and the spike, the number of spikelets and grains in the spike, and the mass of grain per spike were taken into account.

\section{RESULTS AND DISCUSSION}

\section{Identification of the collected bacteria}

Sixty isolates of bacteria were extracted from the rhizosphere, rhizoplane, and endo-sphere of the root system of wheat, 24 strains were identified and assigned to PGPR. Strains that showed growth-promoting properties and other characteristic properties of PGPR bacteria were identified using the MALDI-TOF mass spectroscopy method. The obtained data were analyzed and compared with mass spectra information taken from the Bruker Daltonics electronic library. Comparison of the collection of mass spectra of PGPR strains among themselves confirmed a high degree of kinship between the studied bacteria. According to the results of MALDI-TOF mass spectrometry, 4 strains: $1 / 5 \mathrm{cc}, 3 / 5 \mathrm{cr}, 2 / 5 \mathrm{cr}, 1 / 5 \mathrm{cr}$ were identified as Acinetobacter calcoaceticus (value 2.0-2.4); 4 strains : $1 / 6 \mathrm{kp}, 3 / 4 \mathrm{pp}, 1 / 6 \mathrm{pp}, 4 / 5 \mathrm{kp}$ were identified as Pseudomonas koreensis (value 2.0-2.2); 2 strains: 1/1c and 8P were identified as Stenotrophomonas rhizophila (2.0 value); 2 strains: $2 / 6 \mathrm{kp}$ and 2/4 pp were identified as Arthrobacter species (2.1 value); 3 strains: $2 / 1$ c, $6 \mathrm{AB}$ and 3C5 were identified as Bacillus species (value 2.0); 1 strain: 5/4 pp was identified as a Rhizobium radiobacter (value 2.4); 3 strains: $1 / 7 \mathrm{cc}, 1 \mathrm{~h}$ and E2 were identified as Pseudomonas species (value 1.7-2.0); 1 strain: 1/3c was identified as Agromyces cerinus (2.0 value).

Cultures that failed to be identified on the mass spectrometer due to their absence in the database were identified by genotyping. During genetic identification of the strains: 1 Ac, 1/3 Ac, 3/1 Ac, 1/5 Ac, 8P and 2/1M based on the analysis of the nucleotide sequence of the 16rRNA gene after removal of the terminal fragments, a nucleotide sequence of $660 \mathrm{bp}$ was obtained. This sequence identified by Gene Bank using the BLAST algorithm. When identified using the international NCBI database, the identified 1/3 Ac strain was maximally identical (99.45\%) with Azotobacter chroococcum strain. However, taking into account the literature data indicating the presence of nucleotide sequence errors in international banks such as GenBank and the Ribosomal Database Project (RDP-II), an additional phylogenetic tree was constructed with the nucleotide sequences of the 16S rRNA gene of the reference strains of this species (Figure 1) (NCBI National Center for Biotechnology Information, USA.). It was shown that the nucleotide sequences of the 1/3 Ac strain, when identified in Gene Bank, formed a separate phylogenetic branch, different from the branches of $R$. leguminosarum and S. rhizophila, respectively.

The nucleotide sequence analysis of the $16 \mathrm{~S}$ rRNA gene showed belonging to strains $1 \mathrm{Ac}, 1 / 5 \mathrm{Ac}, 3 / 1 \mathrm{Ac}$, and $1 / 3$ Ac to the genus Azotobacter. Strain 1 Ac had $99 \%$ identity with Azotobacter chroococcum only. Strain 2/1M had $98.8 \%$ identity only with Rhizobium leguminosarum.

Laboratory and vegetation tests of the associative bacteria influence on the yield of cereal crops were conducted in the laboratory. The results of the effect of growth-promoting bacteria on germination of wheat seeds are presented in Figure 2 and Table 1.

The seeds were treated with strains of growthstimulating rhizobacteria. As a result, the germination was increased to $85-100 \%$, while in the control germination it was only $30 \%$. In addition, stimulation of the growth of the roots of seedlings and stems was observed in almost all variants of the experiment (Figure 2, Table 1).

To assess the ability of FMB strains to mobilize phosphorus from insoluble phosphates, an experiment was conducted with strains of Pseudomonas koreensis $4 / 5 \mathrm{cr}$, Acinetobacter calcoaceticus $2 / 5$ pr, Pseudomonas brassicacearum 1/7cc, Pseudomonas koreensis 3/4 pr and Acinetobacter calcoaceticus $1 / 5$ pr grown for 15 days in the media of Novogrudskiy.
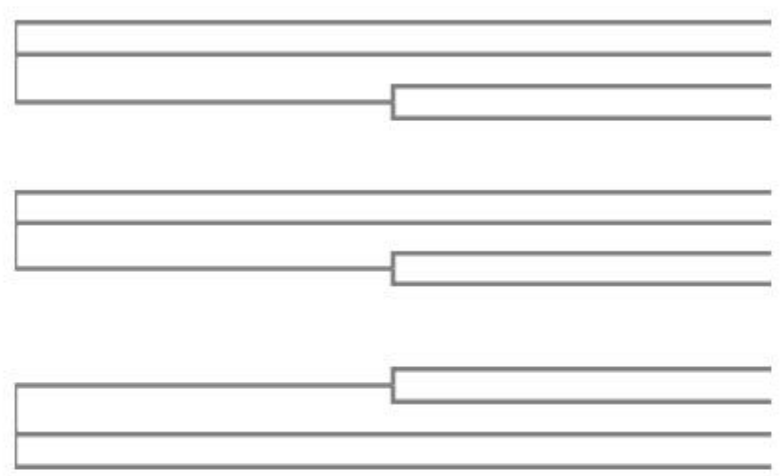

Rhizobium_leguminosarum_ 0.11386

Stenotrophomonas rhizophila 0.07621

Azotobacter_chroococcum_NR__041035.10.02214 $1 / 3 \mathrm{AC}-0.01 \overline{6} \overline{6} 6$

Rhizobium_leguminosarum_0.11386

Stenotrophōmonas rhizophila 0.07621

Azotobacter_chroococcum_NR_041035.10.02214

$1 \mathrm{Ac}-0.016 \overline{6} \overline{6}$

2/1M 0.47382

Rhizobium leguminosarum 0.0914

Stenotrophōmonas_rhizophila_0.07495

Azotobacter_chroococcum_NR_041035.10.0762

Figure 1. Phylogenetic tree constructed on the data of gene fragment analysis 16S rRNA Azotobacter Group 


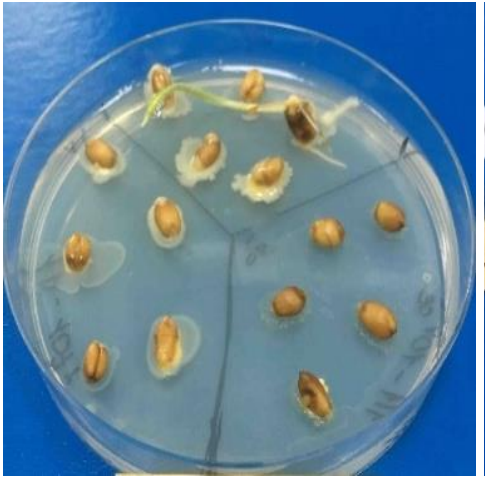

A

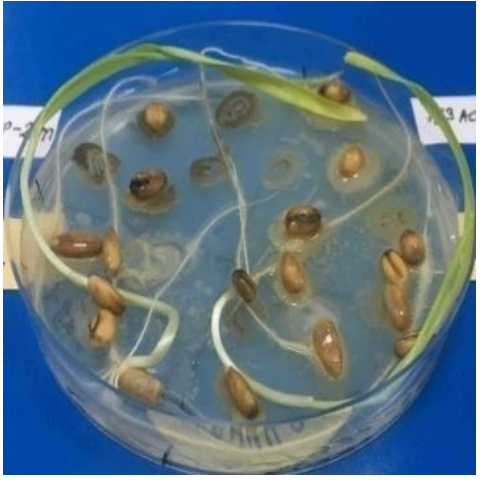

B

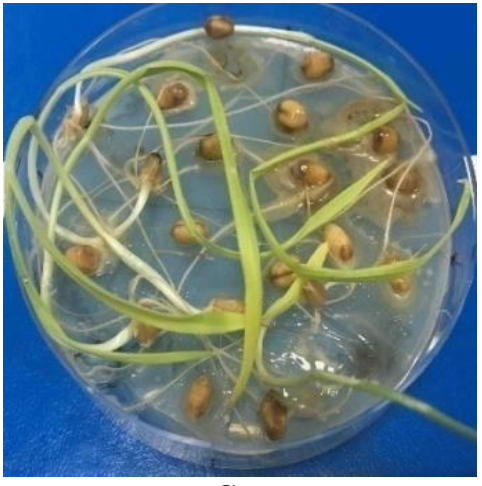

C

Figure 2. The influence of associative bacteria strains on the seedlings growth and root formation of wheat cultivar "Astana-2" control (without treatment) (A), seed inoculation with AVB strains-1-st day (B), seed inoculation with PGPR strains-3-rd day (C)

The following results were obtained on the activity of phosphate mobilization by strains: No. 4-Acinetobacter calcoaceticus $2 / 5$ pr; No. 5-Pseudomonas brassicacearum $1 / 7 \mathrm{cc}$; No. 7-Pseudomonas koreensis 4/5 kp; No. 12Pseudomonas koreensis 3/4 pr; No. 14-Acinetobacter calcoaceticus $1 / 5 \mathrm{pr}$, etc. Studies have shown that after ten days in all cases an increase in the soluble form of phosphorus is detected (Figure 3).

At a constant level of the soluble phosphorus fraction in the sterile control $(3.1 \mathrm{mM} / \mathrm{L})$, the increase in soluble phosphorus by the biomass of the Acinetobacter calcoaceticus $1 / 5 \mathrm{pr}$ strain and Pseudomonas koreensis 4/5 $\mathrm{kp}$ was $25.5 \mathrm{mM} / \mathrm{l}$, the biomass of the Pseudomonas brassicacearum 1 strain $/ 7 \mathrm{cc}-27.0 \mathrm{mM} / \mathrm{L}$, biomass of the Pseudomonas koreensis strain $3 / 4$ ol- $34.3 \mathrm{mM} / \mathrm{L}$, biomass of the Acinetobacter calcoaceticus strain $2 / 5$ pr ol-30.0 $\mathrm{mM} / \mathrm{L}$.

According to the results of the study on the soluble phosphates, five promising phosphate mobilizing strains were selected. The evaluation of the activity of phosphate mobilization strains led to detection of the five strains of FMB, the most active strains was Acinetobacter calcoaceticus $2 / 5$ ol-30.0 mM/L, Pseudomonas koreensis $3 / 4$ ol-34,3 mM/L, Pseudomonas brassicacearum $1 / 7 \mathrm{cc}-$ $27.0 \mathrm{mM} / \mathrm{L}$. Strains of Pseudomonas koreensis 1/5 ol-25.0 $\mathrm{mM} / \mathrm{L}$ and Pseudomonas koreensis $4 / 5 \mathrm{cr}-25.5 \mathrm{mM} / \mathrm{L}$ was slightly less active.

The nitrogen-fixing ability of bacterial strains was established by a yellow-green color around the colony of strains, which indicates the accumulation of ammonia in the medium (NFMM), are presented in Figure 4.

Nitrogen fixation strains were tested for their ability to accumulate ammonium on solid nitrogen-free media. Based on the acquired data, it was found out that the strains of Azotobacter, i.e.: Rhizobium sp 2/1M, Azotobacter chroococcum 3/1Ac; Stenotrophomonas rhizophila 8P, Azotobacter chroococcum 1/1Ac, Rhizobium nepotum 2/2 Ac, Pseudomonas koreensis 2/1 Al, Beijerinckia fumines 1/1 M, Paenarthrobacter nitroguajacolicus 1 Al provided an increase in ammonia, which indicates their ability to fix atmospheric nitrogen.
The strains of fungi Alternaria alternata and Fusarium $s p$. (the collection of the plant genomics and bioinformatics laboratory, "National Center for Biotechnology" NurSultan city, Kazakhstan) were used as testing objects (determination of determining Antagonistic spectrum). In fact, these fungi are the causative agents of the most common plant diseases. Antagonism of the AVM was tested on Petri dishes with PGA and Saburo medium by the counter-culture method, and the antifungal activity of growth-stimulating rhizobacteria by diffusion into agar was also investigated in the work. The activity of isolates was studied on 2 phytopathogens in Petri dishes with PGA by the method of holes. As pathogens, fungi of the genera Alternaria alternata and Fusarium sp. AVM activity was observed to varying degrees of intensity in relation to the studied pathogens. The manifestation of the antagonistic and antifungal activity of AVM bacteria strains with respect to phytopathogenic fungi is presented in Figure 5.

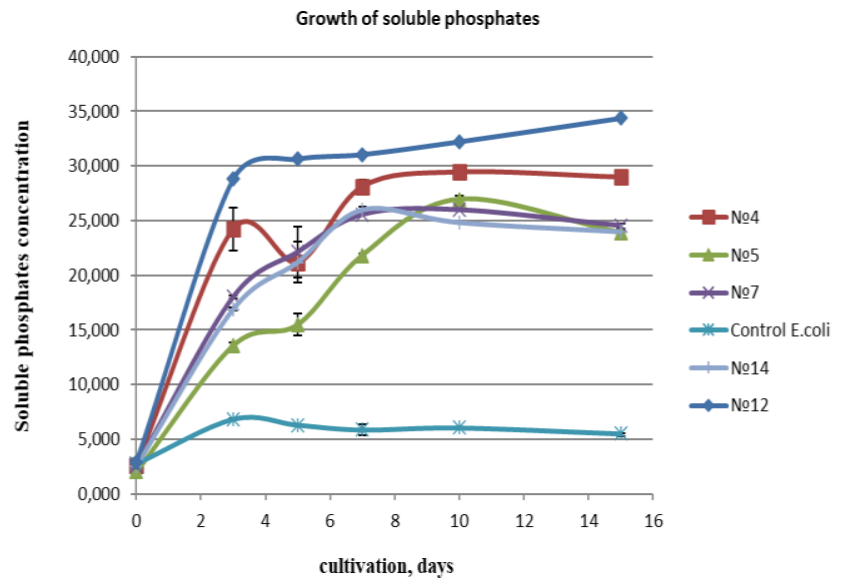

Figure 3. Dynamics of the formation of mobile forms of phosphorus by phosphate-mobilizing bacteria 
Table 1. The growth-promoting bacteria effect on the biometric parameters of 14-day-old wheat seedlings

\begin{tabular}{lccc}
\hline \multicolumn{1}{c}{ Variants } & $\begin{array}{c}\text { Seed germination } \\
(\boldsymbol{\%})\end{array}$ & $\begin{array}{c}\text { Average length of the seedling } \\
(\mathbf{c m})\end{array}$ & $\begin{array}{c}\text { Average root length } \\
(\mathbf{c m})\end{array}$ \\
\hline Control & 30 & $3.20 \pm 0.50$ & $1.60 \pm 0.16$ \\
Pseudomonas koreensis-1/5 pr & 100 & $4.09 \pm 0.18$ & $1.13 \pm 0.20$ \\
Rhizobium spp-2/1 M & 90 & $7.88 \pm 0.65$ & $9.77 \pm 1.99$ \\
Pseudomonas koreensis 3/4 pr & 100 & $3.05 \pm 0.79$ & $5.20 \pm 0.57$ \\
Acinetobacter calcoaceticus-2/5 pr & 100 & $6.45 \pm 0.51$ & $7.65 \pm 1.47$ \\
Azotobacter chroococcum-1Ac & 90 & $5.83 \pm 0.92$ & $9.44 \pm 2.38$ \\
Pseudomonas koreensis-1/6 pr & 100 & $4.84 \pm 0.69$ & $5.23 \pm 0.81$ \\
Bacillus mojavensis & 85 & $4.58 \pm 0.50$ & $15.2 \pm 0.16$ \\
Arthrobacter boritolerans-4 ch & 85 & $3.32 \pm 0.35$ & $3.14 \pm 0.38$ \\
Pseudomonas koreensis-4/5 kr & 80 & $7.25 \pm 1.16$ & $9.75 \pm 2.35$ \\
Azotobacter chroococcum-1/5 Ac & 100 & $2.37 \pm 0.27$ & $6.14 \pm 0.84$ \\
\hline
\end{tabular}

Table 2. The effect of the bacterial association of AVB on the biometric indicators of wheat seedlings of the Astana-2 variety (after 21 days of laboratory micro-vegetation experience) 05.24.19-06.15.19

\begin{tabular}{|c|c|c|c|c|c|c|c|c|c|}
\hline \multirow[t]{2}{*}{ Variants } & \multirow{2}{*}{$\begin{array}{c}\begin{array}{c}\text { No. of } \\
\text { sown seeds } \\
\text { piece }\end{array} \\
\end{array}$} & \multicolumn{2}{|c|}{$\begin{array}{c}\text { Labs } \\
\text { germination }\end{array}$} & \multirow{2}{*}{$\begin{array}{l}\text { Total plant } \\
\text { length }(\mathrm{cm})\end{array}$} & \multirow{2}{*}{$\begin{array}{l}\text { Stem length } \\
(\mathrm{cm})\end{array}$} & \multirow{2}{*}{$\begin{array}{c}\text { Root length } \\
(\mathrm{cm})\end{array}$} & \multirow{2}{*}{$\begin{array}{l}\text { Total wet } \\
\text { weight of } \\
\text { plants (g) }\end{array}$} & \multirow{2}{*}{$\begin{array}{l}\text { Wet weight } \\
\text { of stems (g) }\end{array}$} & \multirow{2}{*}{$\begin{array}{l}\text { Wet weight } \\
\text { of roots (g) }\end{array}$} \\
\hline & & Amount & $\%$ & & & & & & \\
\hline Control & 10 & 4 & 40 & $32.6 \pm 1.5$ & $19.2 \pm 0.7$ & $13.1 \pm 0.3$ & $0.3 \pm 0.2$ & $0.2 \pm 0.17$ & $0.1 \pm 0.1$ \\
\hline Consortium No.1 & 10 & 8 & 80 & $54.5 \pm 0.7$ & $30.0 \pm 0.8$ & $24.5 \pm 0.1$ & $0.8 \pm 0.4$ & $0.5 \pm 0.4$ & $0.3 \pm 0.2$ \\
\hline Bs.mojavensis & 10 & 9 & 90 & $47.3 \pm 0.3$ & $27.3 \pm 0.4$ & $20.0 \pm 0.1$ & $0.6 \pm 0.13$ & $0.37 \pm 0.07$ & $0.29 \pm 0.3$ \\
\hline
\end{tabular}

As the data in Figure. 5 shows, as a result of the antagonistic action of the AVM bacterium on phytopathogenic fungi around the bacterial colonies, the absence of the fungal growth zone is observed. The most powerful antagonistic and antifungal properties in relation to Fusarium sp. and Alternaria alternata possessed bacteria Bacillus spp.-2/1c, Pseudomonas spp.-4/5kr, Rhizobium spp-2/1M, Stenotrophomonas spp.-8P, Azotobacter spp.1 Ac.

The results of pre-sowing treatment of PGPR with bacteria for the development of wheat plants in a microvegetation experiment are shown in Table 2.

Based on the data provided in Table 5, under the influence of presowing treatment of wheat seeds with strains of associative rhizobacteria, there was observed a stimulating effect on the growth and development of wheat plants. At the same time, the plant germination increased 1.5-2.5 times, the length of the stem 1.3-2 times, the root 1.2-2 times, the wet weight of one plant was 1.2-2.5 times compared with the control variant. According to the results, one association and one strain of rhizobacteria (Consortium No. 1, and B. mojavensis), which has the highest positive effect on the development of wheat plants, were selected.

In the growing experiment, it was studied the effect of consortia of rhizobacteria selected from the results of micro-growing experiments on the wheat crop. The experimental data are presented in Figure 5 and Table 3.

From the data of Table 3, it can be seen that the maximum increase in wheat grain yield was observed in variants with numbers $3,7,8,9,10,11$, and 12 , which exceeded all three controls. The use of AVB increased wheat yield by $67 \%-156.4 \%$ compared with the control option (without fertilizer). According to the research results, an association of rhizobacteria was created, which included strains that have the highest positive effect on the development and productivity of spring wheat.

Evaluation of the effectiveness of a complex preparation was carried out in the field. The field small-plot experiment was laid in the fields belonging to the SPCGF named by A.I. Barayev. According to the structural analysis conducted in 2019, the following results were obtained: the productive business of spring soft wheat varieties fluctuates from 2 pcs. up to 3 pcs. In control, this indicator was at the level of 2 pcs. The average height of plants in the studied experiments is $59.3+1.0 \mathrm{~cm}$. Coefficient of variation $\bullet 4.22 \%$, i.e., they are quite similar in height of plants. Reliably superior in height to the samples in experiments K-1 (and K-3-62 cm). The quantity and mass of the formed caryopsis depend on the length and density of the ear. On this basis, samples were distinguished in experiments $\mathrm{K}-1, \mathrm{~K}-3$, and $\mathrm{B}(9 \mathrm{~cm})$, exceeding the control by $1 \mathrm{~cm}$. In the spike productivity, the basic indicator is the number of spikelets in the spike, since this structural element is laid and formed first. The number of spikelets ranged from 26 to 27 pcs. The ear content of an ear is primarily determined by the number of spikelets formed on the protrusions of the ear stem. The more spikelets, the more grains in an ear and the mass of grain from one ear (Kovtun 2015). The number of grains from the main spike in experiment B was 29, which is at the control level. The mass of grain from an ear varied from $0.95 \mathrm{~g}$ to $1.24 \mathrm{~g}$. This indicator was higher in the $\mathrm{K}-3$ experiment variants $(1.24 \mathrm{~g})$. A low grain weight from the main ear was detected in the control $(0.95 \mathrm{~g})$ (Figure 6).

The greatest mass of seeds from one plant was observed in the samples in experiment B-2.29 g, the smallest in the 
control was- $1.69 \mathrm{~g}$. In terms of productivity, the samples in experiment B (15.72 c/ha) and K-1 (14.38 c/ha) were distinguished, in comparison with the control $(12.49 \mathrm{c} / \mathrm{ha})$ (Table 4).

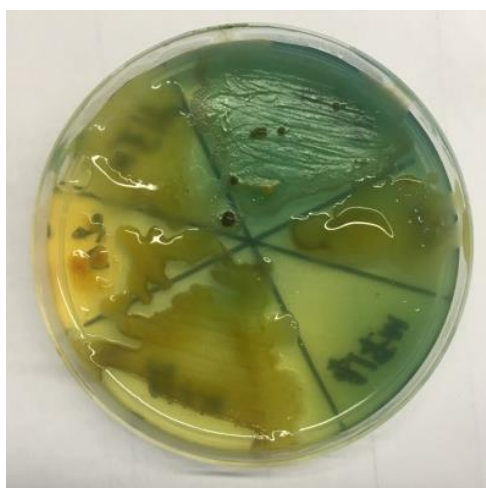

A

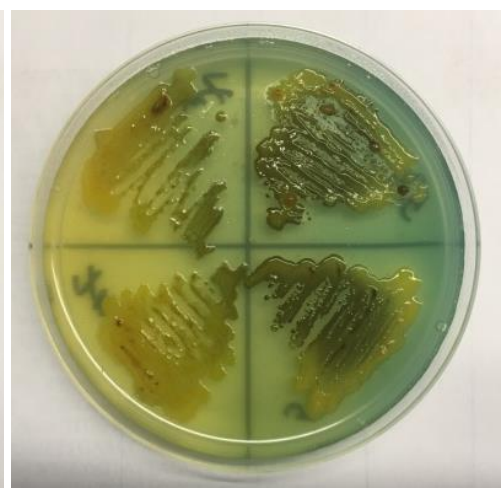

B

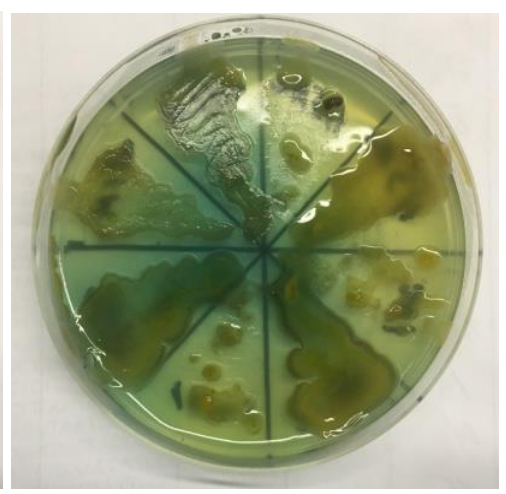

C

Figure 4. Qualitative determination of the nitrogen-fixing ability of bacterial strains on a nitrogen-free mineral medium (NFMM) strain Rhizobium sp 2/1M (A), strain Azotobacter chroococcum 3/1 Ac (B), Stenotrophomonas rhizophila 8P strain (C)

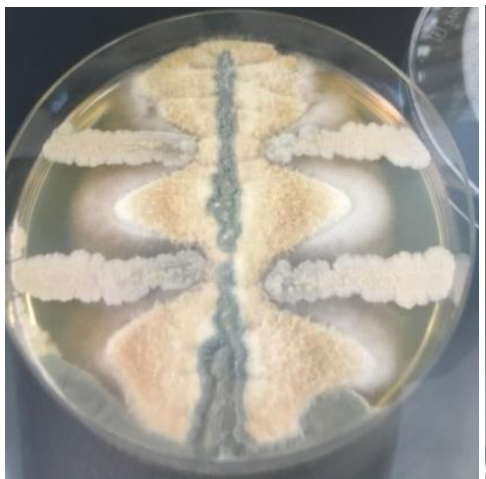

A

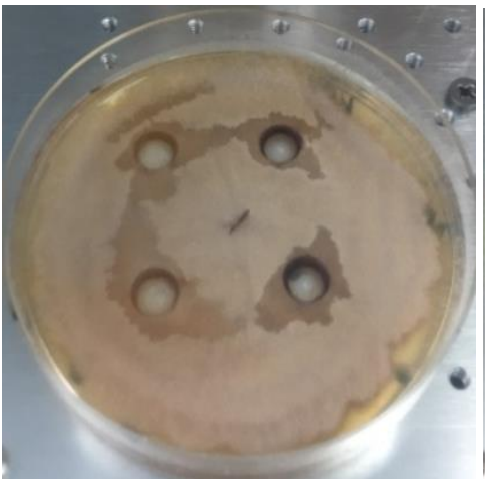

B

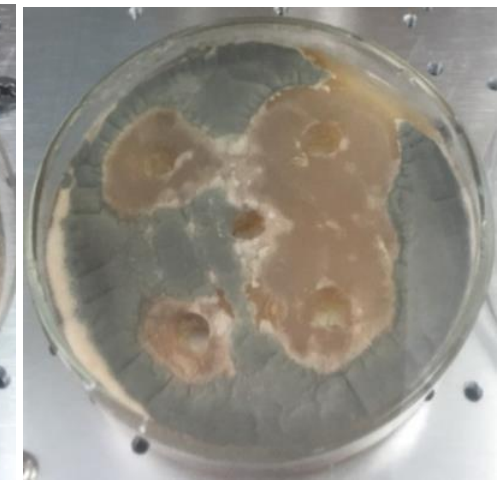

C

Figure 5. Antagonistic and antifungal activity of AVM strains. Antagonistic effect of AVM strains on a fungus of the genus Alternaria alternata (A), Antifungal activity of AVM strains in relation to fungi of the genus Fusarium sp. and Alternaria alternata (B, C)

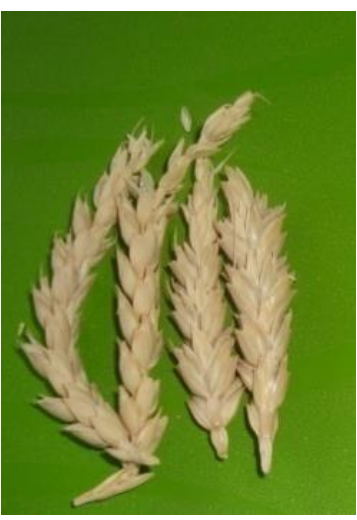

A

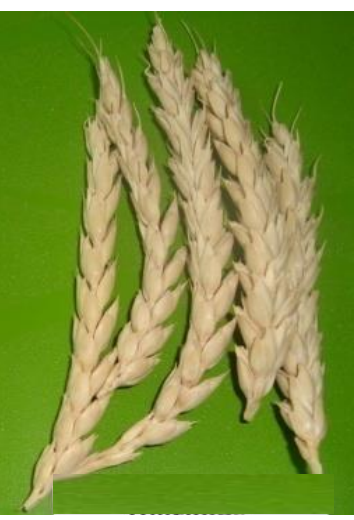

B

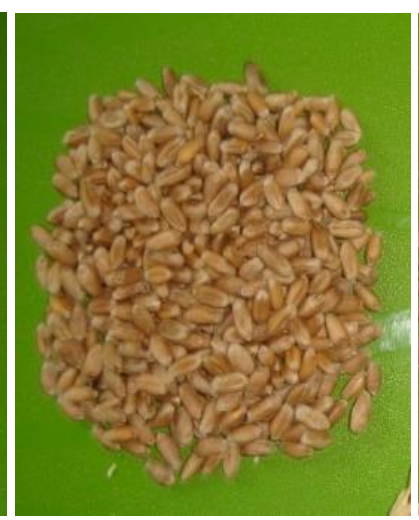

C.1

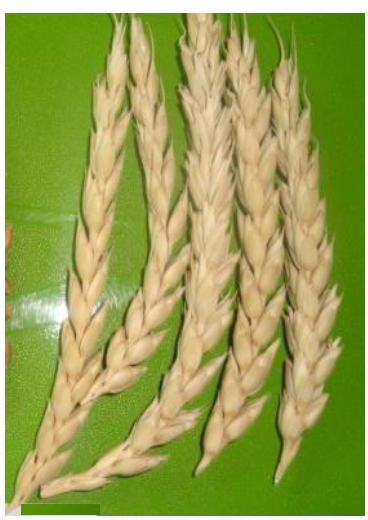

C.2

Figure 6. The effect of growth-stimulating rhizobacteria on the yield of grain of the wheat variety Astana 2. Control (without processing) (A), experience on the right seed inoculation with AVB isolates (B, C) 
Table 3. The Impact of individual strains of PGPR bacteria that are part of the consortium on the productivity of spring wheat cultivar "Astana-2"

\begin{tabular}{lccc}
\hline \multicolumn{1}{c}{ Variants } & Number of sown seeds & $\begin{array}{c}\text { Productivity per vessel } \\
(\mathbf{1 0} \text { pieces of plants) }\end{array}$ & $\begin{array}{c}\text { Yield increase } \\
(\boldsymbol{\%})\end{array}$ \\
\hline Control 1-(without M/F) & 10 & 2.98 & 0 \\
Control 2-Bacillus mojavensis & 10 & 4.98 & 67.0 \\
Acinetobacter calcoaceticus-2/5 pr & 10 & 5.96 & 100 \\
Pseudomonas koreensis-1/6 pr & 10 & 5.29 & 75.0 \\
Bacillus mojavensis & 10 & 4.98 & 67.0 \\
Rhizobium sp.-2/1M & 10 & 2.78 & 6.71 \\
Azotobacter chroococcum-1Ac & 10 & 7.64 & 156.4 \\
Azotobacter chroococcum-1/5Ac & 10 & 5.88 & 97.3 \\
Agromyces cerinus-1/35c & 10 & 6.56 & 120.1 \\
Azotobacter chroococcum-1/3Ac & 10 & 5.77 & 93.62 \\
Bacillus mucilaginosus-3C5 & 10 & 5.22 & 75.17 \\
Stenotrophomonas rhizophila-8P & 10 & 5.40 & 81.2 \\
\hline
\end{tabular}

Table 4. Structural indicators and yield of spring wheat cultivar "Astana-2" in the field experiment

\begin{tabular}{|c|c|c|c|c|c|c|c|c|c|c|}
\hline \multirow{3}{*}{$\begin{array}{c}\text { Experiment } \\
\text { no. }\end{array}$} & \multicolumn{2}{|c|}{ Vegetational period } & \multirow{3}{*}{$\begin{array}{l}\text { Product- } \\
\text { ivity } \\
\text { (c/ha) }\end{array}$} & \multirow{3}{*}{$\begin{array}{c}\text { Plant } \\
\text { height } \\
(\mathrm{cm})\end{array}$} & \multirow{3}{*}{$\begin{array}{c}\text { Length } \\
\text { (cm) }\end{array}$} & \multirow{2}{*}{\multicolumn{3}{|c|}{ Spike }} & \multirow{2}{*}{\multicolumn{2}{|c|}{ Plant }} \\
\hline & \multicolumn{2}{|c|}{ (days before) } & & & & & & & & \\
\hline & Heading & Maturation & & & & $\begin{array}{l}\text { Amount of } \\
\text { spikelets } \\
\text { (piece) }\end{array}$ & $\begin{array}{l}\text { Amount of } \\
\text { grains } \\
\text { (piece) }\end{array}$ & $\begin{array}{c}\text { Grain weight } \\
\text { of the main } \\
\text { ear }(\mathrm{g})\end{array}$ & $\begin{array}{l}\text { Amount } \\
\text { of grains, } \\
\text { piece }\end{array}$ & $\begin{array}{l}\text { Weight of } \\
\text { grain (g) }\end{array}$ \\
\hline Control & 50 & 88 & 12.49 & 56 & 8 & 27 & 29 & 0.96 & 60 & 1.69 \\
\hline $\mathrm{K}-1$ & 48 & 88 & 14.38 & 62 & 9 & 26 & 27 & 1.03 & 66 & 2.07 \\
\hline B & 48 & 87 & 15.72 & 57 & 9 & 27 & 29 & 0.98 & 69 & 2.29 \\
\hline $\max$ & 50 & 89 & 15.72 & 62 & 9 & 27 & 29 & 1.24 & 69 & 2.29 \\
\hline $\min$ & 48 & 87 & 12.49 & 56 & 8 & 26 & 27 & 0.88 & 60 & 1.69 \\
\hline
\end{tabular}

Table 5. The effect of associative bacteria AVM on the quality indicators of grain of the wheat variety Astana 2

\begin{tabular}{lccc}
\hline Variant & Protein (\%) & $\begin{array}{c}\text { Amount of gluten } \\
(\%)\end{array}$ & $\begin{array}{c}\text { Quality of } \\
\text { gluten }(\boldsymbol{\%})\end{array}$ \\
\hline Control & 14.37 & 27.18 & 72 \\
K 1 & 14.82 & 27.92 & 73 \\
Э & 14.86 & 27.56 & 73 \\
B & 14.75 & 27.85 & 73 \\
\hline
\end{tabular}

Based on the results of the studies on the elements of the crop structure of the Astana 2 spring wheat variety, the following results were revealed: productive bushiness in experiments K-1 (Acinetobacter calcoaceticus-2/5 pr, Pseudomonas koreensis-1/6 pr, Bacillus mojavensis, Rhizobium sp.-2/1M), K-2 (Pseudomonas frederiksbergensis-1/25 $\mathrm{s}$, Acinetobacter calcoaceticus1/5pr, Arthrobacter boritolerans-4 ch, Azotobacter chroococcum-1Ac, K-3 (Bacillus pumilus-6AB, Bacillus mucilaginosus-3C5, Stenotrophomonas rhizophila-8P), BBacillus mojavensis, E-Pseudomonas hibiscicola was at the level of 3 pcs. This indicator in the control was 2 pcs. In experiment $\mathrm{B}$, a high amount of grain from the main spike was 29 pcs, which is at the control level. Grain weight from an ear ranged from $0.95 \mathrm{~g}$ to $1.24 \mathrm{~g}$. Yields ranged from 12.49 in the control to $15.72 \mathrm{~kg} / \mathrm{ha}$ in the test variant B.
The effectiveness of the preparations is confirmed by data on the quality of wheat grains. The results of the analysis of the effective options are presented in Table 5. The use of associative rhizobacteria positively affected the quality of grain. So, the highest protein content and the amount of gluten were noted in experimental variants $\mathrm{K} 1$ 14.82\%-27.92\%; E-14.82\%,-27.56\%; At-14.75\%-27.85\%, relative to the control variant, $14.37 \%-27.18 \%$, respectively.

Thus, according to the results of laboratory and field tests, options K 1 and B-provided a yield increase of 1.89 and $3.23 \mathrm{~kg} / \mathrm{ha}$, respectively. Also, both options were more effective than the drug in option E.

\section{Discussion}

It has been shown that the application of MALDI-TOF mass spectrometry for the microorganism express identification system is necessary for quick and reliable laboratory diagnostics. In turn, it requires the development of standardized approaches for sample preparation, the formation and evaluation of mass spectra, and the interpretation of the results. Moreover, there is a need in appropriate regulation and monitoring of all stages of mass spectrometric analysis.

For example, the identification results of strains by analysis of the 16S rRNA gene fragment can be used as molecular biological characterization of the strains. It was demonstrated that bio-fertilizers prepared from living micro-organisms (applied to the seeds or plant surfaces 
adjacent to soil) can effectively colonize rhizosphere or the interior parts of the plants, and thus, promote roots growth (Bhattacharyya and Jha 2012). In addition, the results of some studies indicated that volatile organic compounds produced by $B$. mojavensis may act as plant growth modulators rather than just promoters (Rath et al. 2018).

Direct mechanisms of plant growth-promoting by PGRP group bacteria include the production of auxin, g 1aminocyclopropane1-carboxylate (ACC) deaminase, cytokinin, gibberellin, nitrogen fixation, phosphorous solubilization, and sequestration of iron by bacterial siderophores. It has been thought that the indirect mechanism is based on the inhibition activity of the plant pathogenic organisms (fungi and bacteria) (Olanrewaju et al. 2017).

Our data showed the potential of PGPR group bacteria for the development of biofertilizers and biopesticides. The bacteria $B$. mojavensis has proved to be effective in the experiments with wheat of Astana-2 type. Dunaytsev et al. (2017) tested B. mojavensis Lhv 97 strain in the conditions of chernozems of the Ryazan region under Agata wheat, but our preparation has been shown to be effective in extremely adverse weather conditions. The preparation in the field experiments provided an increase in wheat yield by $15 \%$, and in conditions of artificial infection of crops with snow mold, 2.5 times compared with the control. The results of the previously published studies and our results allow us to recommend the B. mojavensis Lhv 97 strain for further testing as the active principle of a biological product against plant diseases caused by phytopathogenic fungi.

Bacon and Hinton (2007) demonstrated the positive effect of their patented strain of Bacillus mojavensis RRC 101 on improving the growth and rate of development of wheat, including corn, shrub beans (Phaseolus vulgaris L.), barley, rye, and Spanish peanuts (Arachis hypogaea L.). Regardless of the mechanism of action, this endophytic bacterium has the great advantage of biocontrol over other bacteria in terms of its single application for wheat seeds. This single-use is a very effective protection against damage to wheat seedlings under controlled conditions. The results of this study showed the possibility of using $B$. mojavensis as a biological control with potential for field applications.

To summarize, based on the available literature data and our results, B. mojavensis culture can be recommended to be used as the basis for biological control preparations, including the phytopathogens of wheat and other cereal plants. In addition, it can be utilized as a component of complex biological products due to its growth-promoting and nitrogen-fixing activity.

\section{ACKNOWLEDGEMENTS}

This study was carried out under the framework of the state program "BR06349586" of the Ministry of Agriculture and in the framework of the project
BR05236334 of the Ministry of Education and Science of the Republic of Kazakhstan. The authors declare no conflict of interest. The sponsors did not play any role in the development of the study, collection, analysis, or interpretation of the data, the writing of the manuscript, and the decision to publish the results.

\section{REFERENCES}

Backer R, Rokem JS, Ilangumaran G, Lamont J, Praslicova D, Ricci E, Subramanian S, Smith DL. 2018. Plant growth-promoting rhizobacteria: context, mechanisms of action, and roadmap to commercialization of biostimulants for sustainable agriculture. Front Plant Sci 9: 1473. DOI: 10.3389/fpls.2018.01473.

Bacon CW, Hinton DM. 2007. Potential for control of seedling blight of wheat caused by Fusarium graminearum and related species using the bacterial endophyte Bacillus mojavensis. Biocontrol Sci Technol 17: 81-94.

Bhattacharyya PN, Jha DK. 2012. Plant growth-promoting rhizobacteria (PGPR): emergence in agriculture. World J Microbiol Biotechnol 28 (4): 1327-1350.

Cruz-González X, Laza-Pérez N, Mateos PF, Rivas R. 2017. Analysis and effect of the use of biofertilizers on Trifolium rubens L., a preferential attention species in Castile and Leon, Spain, with the aim of increasing the plant conservation status. AIMS Microbiol 3 (4): 733 746.

Dingle TC, Butler-Wu SM. 2013. Maldi-tof mass spectrometry for microorganism identification. Clin Lab Med 33 (3): 589-609.

Dospekhov BA. 2012. Field experience technique. Book on-demand. Moscow. [Russian]

Dunaytsev IA, Lev IO, Klykova MV, Zhigletsova SK, Antoshina OA, Kolombet LV. 2017. The efficacy of the strain of Bacillus mojavensis Lhv 97 for increasing wheat yield. Agrochemistry 4: 76-82. [Russian]

Gange AC, Gadhave KR. 2018. Plant growth-promoting rhizobacteria promote plant size inequality. Sci Rep 8 (1): 13828.

Kumari B, Mallick MA, Solanki MK, Solanki AC, Hora A, Guo W. 2019. Plant Growth Promoting Rhizobacteria (PGPR): Modern prospects for sustainable agriculture. In: Ansari R, Mahmood I (eds) Plant Health Under Biotic Stress der Biotic Stress. Springer, Singapore.

Kovtun VI. 2015. Graininess, mass of grain per ear and mass of 1000 grains in increasing the yield of winter soft wheat. News of the Orenburg State Agrarian University 3: 27-29. [Russian]

Kuhn, C, Grof CP. 2010. Sucrose transporters of higher plants. Curr Opin Plant Biol 13: 288-298.

Luna T, Wilkinson K, Kasten, Dumroese R. 2014. Seed germination and Sowing options. Nursery Manual for Native Plants Agriculture Handbook 1: 133-151.

Majeed A, Abbasi MK, Hameed S, Imran A, Rahim N. 2015. Isolation and characterization of plant growth-promoting rhizobacteria from wheat rhizosphere and their effect on plant growth promotion. Front Microbiol 6: 198.

Olanrewaju OS, Glick BR, Babalola OO. 2017. Mechanisms of action of plant growth-promoting bacteria. World J Microbiol Biotechnol 33 (11): 197.

Rath M, Mitchell TR, Gold SE. 2018. Volatiles produced by Bacillus mojavensis RRC101 act as plant growth modulators and are strongly culture-dependent. Microbiol Res 208: 76-84.

Sharifi RS, Khavazi K. 2011. Effects of seed priming with Plant Growth Promoting Rhizobacteria (PGPR) on yield and yield attribute of maize (Zea mays L.) hybrids. J Food Agric Environ 9: 496-500.

Smith DMc, Cluskey K, Stackebrandt E. 2014. Investment into the future of microbial resources: culture collection funding models and BRC business plans for biological resource centers. Springer Plus 81: 12 .

Shirokih AA, Merzaeva OV, Shirokih IG. 2007. Methodological approaches to the study of microorganisms of the root zone of plants. Agric Biol 1: 43-55. [Russian]

Umesha S, Singh PK, Singh RP. 2018. Microbial biotechnology and sustainable agriculture. In: Singh RL, Mondal S (eds) Biotechnology for Sustainable Agriculture. Woodhead Publishing, Sawston. 